\title{
Alternative Methods of Estimating Snow Water Parameters
}

\author{
David L. Regse ${ }^{1}$ \\ Water Resources Research Institute, University of Idaho, Kimberly, Idaho 89941 \\ H. F. MAYLAND \\ USDA Snake River Conservation Research Center, Agricultural Research Service \\ Kimberly, Idaho 89341 \\ Charles E. Brockway \\ Water Resources Research Institute, University of Idaho, Kimberly, Idaho 89941
}

\begin{abstract}
A recurrence analysis technique using probability and contingency relationships of snow depth, water equivalent, and snow density is presented. Three methods of estimating snow water parameters at site $\mathrm{A}$ by recurrence and the presently used regression techniques are based on (1) the value from the previous month at site $A$, (2) the value from a reference site, and (3) the month to previous month contingency parameter of the reference course. The recurrence technique (Pearson type 3 ) when it was tested on three central Idaho snow courses was most useful when method 3 was used to estimate snow depth and either method 1 or 3 was used to estimate the water equivalent. Correlation of estimated values to measured values indicated equal reliability of recurrence and regression analysis when the three methods were used. The recurrence technique can successfully be used in estimating snow water parameters and their probability of occurrence. This technique like the regression technique requires a basic data set before it can be applied.
\end{abstract}

A reasonably accurate and reliable method is required for estimating snow depths and water equivalent values when it is either impossible or undesirable to measure them. Standard regression techniques are available; however, they provide no insight into the frequency distribution or probable recurrence intervals. The Pearson type 3 recurrence analysis technique provides an additional means of estimating snow depth, water equivalent, and snow density.

In this paper the term snow water parameter includes both the snow depth and the water equivalent of the snow pack as well as the dimensionless computed water:snow depth ratio (density). The term recurrence interval is defined as the computed percent probability level at which a given event is expected to occur or reoccur. The contingency ratio is defined as

\footnotetext{
${ }^{1}$ Now with the U.S. Army Corps of Engineers, Walla Walla, Washington.
}

Copyright (C) 1973 by the American Geophysical Union. the ratio of a particular snow water parameter to the same measurement made the preceding month for the same site. All snow water parameters used in this paper represent approximately first of the month measurements. Thus an April : March snow depth contingency ratio would mean the snow depth on April 1 for a particular site divided by the snow depth on March 1 of the same year for the same site.

\section{Methods and Procedures}

Snow survey data [Soil Conservation Service, 1921-1964, 1965-1971] were analyzed for 12 snow course sites in the western United States. Four central Idaho sites in the Big Wood River drainage (Figure 1) were selected to illustrate the estimating procedures. Data were available for January through April; however, since the spring snow water parameters are generally of greater interest than parameters for other seasons for runoff and flood forecasting, only the March and April parameters were used to show the various procedures. Contingency ratios were computed for each parameter. By use of both 


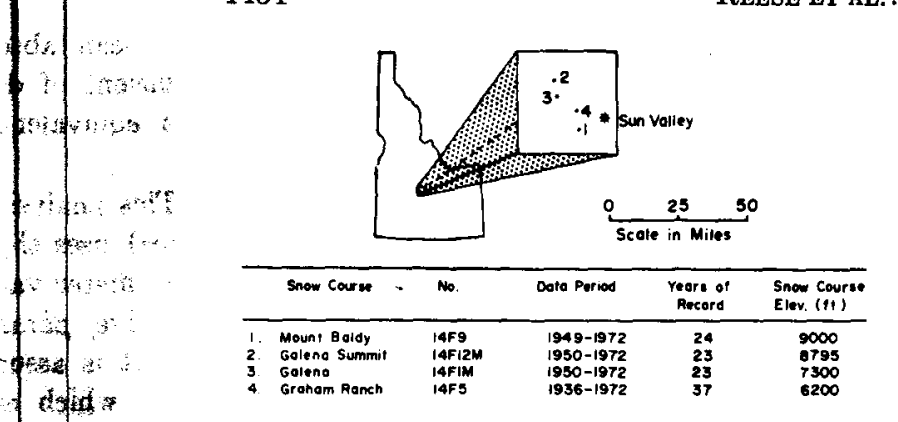

Fig. 1. Central Idaho snow courses on the Big Wood River drainage used for the Pearson type 3 method analysis.

the probability recurrence analysis and the regression analysis the reliability of the developed relationships for estimating the snow water parameters was evaluated. Data used in developing the probability, or recurrence, curves or the regression analyses were those for the data periods and sites shown in Figure 1 except that the 1972 data were excluded.

\section{Frequency Analysis}

A series frequency analysis of the snow depths, water equivalents and densities, and the three corresponding contingency ratios was made for each snow course site. Each event within a particular series or data set (e.g., April snow depths, 1950-1971, Galena Summit) was then ranked (largest first), and the formula $M /(N+1)$, where $M$ is the rank and $N$ is the number of observed events, was used to compute the plotting positions representing the expected probabilities of the ranked events [Langbein, 1960]. The Pearson type 3 method, commonly used in runoff analysis [U.S. Water Resources Council, 1967] was selected to fit the computed plotting positions, since it was found applicable to snow data [Vance and Whaley, 1971].

The Pearson type 3 probability curve was found to describe adequately the frequency series of actual snow water measurements for the Mount Baldy snow course (Figure 2), three adjacent courses (data not shown), and seven courses (data not shown) throughout the northwestern United States.
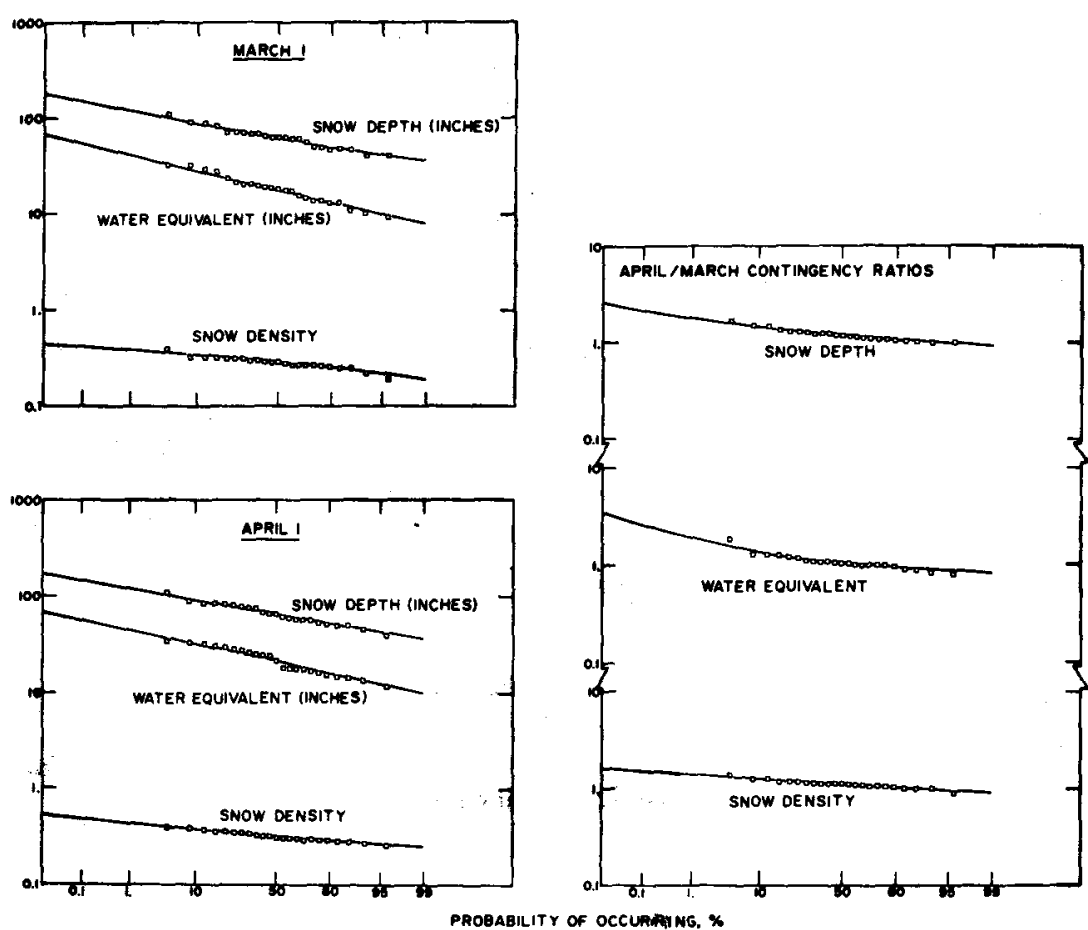

Fig. 2. Recurrence curves from the Mount Baldy snow course. Squares represent the ranked data for each parameter, and the solid line is the Pearson type 3 fit. 


\section{Recurrence Estimating Methods}

Three recurrence methods were used to estimate snow water parameters.

Method 1. This analysis method (equal month to month recurrence) uses the recurrence interval of a selected parameter value for a given month as a basis to forecast the respective parameter value for the succeeding month at the same site. The method is based on the assumption that the recurrence intervals of a given snow water parameter are equal for the two successive months. Suppose a March water depth of 19.9 inches was measured at the Galena Summit site and that a prediction of the April Galena Summit water equivalent for that same year is desired. As is shown in Table 1 , this water equivalent (19.9 inches) has a $50 \%$ recurrence interval, and the assumption of method 1 is that the April water equivalent would then also have a $50 \%$ recurrence interval. Thus the forecasted April water equivalent at Galena Summit would be 24.7 inches.

The assumption that the Galena Summit water equivalent recurrence intervals for March and April are nearly equal appears valid. The coefficient of regression ( $b$ in $\hat{Y}=a+b X)$ for the water equivalent recurrence intervals for March versus April was 0.96, indicating nearly a 1:1 relationship. The coefficient of determination between actual recurrence intervals of March data and those of April data was 0.91 . A comparison of the estimated and measured April water equivalent values for 1950-
1971 yielded a mean absolute error of $6.2 \%$ and had a coefficient of determination of 0.92 (Table 2, water equivalent, method 1, Galena Summit).

Method 2. This analysis method (equal site to site recurrence) uses the recurrence interval of a selected parameter value at site A to estimate the respective parameter value for an adjacent site $\mathrm{B}$. It is assumed that the recurrence intervals at which each measured event occurs for a given month and site are the same as those expected for each event occurring at the nearby site. For example, the known Mount Baldy April water equivalent of 21.1 inches is at the $50 \%$ recurrence interval (Table 1 ). The April water equivalent expected at Galena Summit would also be at the $50 \%$ recurrence interval. Therefore the estimated April Galena Summit water equivalent would be 24.7 inches (Table 1).

The assumption of method 2 that the Galena Summit and Mount Baldy water equivalent recurrence intervals are nearly equal is verified by a coefficient of regression of $b=0.93$ for the recurrence intervals with a coefficient of determination of 0.95 . The coefficient of determination between the estimated April water equivalent values and the corresponding calculated values for the $1950-1971$ period was 0.83 . Thus $83 \%$ of the variation in the estimated water equivalent values for Galena Summit is accounted for by similar variation in water equivalent values on Mount Baldy (Table 2).

TABLE 1. Computed Recurrence Values for Mount Baldy and Galena Summit Sites

\begin{tabular}{|c|c|c|c|c|c|c|c|c|c|}
\hline \multirow[b]{2}{*}{ Snow Course Frequency Series } & \multicolumn{9}{|c|}{$\%$ Probability of Occurrence } \\
\hline & 95 & 90 & 80 & $50^{*}$ & 20 & 10 & 5 & 4 & 2 \\
\hline \multicolumn{10}{|c|}{ Mount Baldy } \\
\hline \multicolumn{10}{|l|}{ Water equivalent, inches } \\
\hline March 1 & 9.8 & 11.3 & 13.0 & 17.5 & 23.7 & 27.8 & 31.7 & 32.9 & 36.8 \\
\hline April 1 & 12.2 & 14.0 & 16.0 & $21.1^{*}$ & 27.6 & 31.7 & 35.5 & 36.7 & 40.3 \\
\hline April: March contingency water & 0.99 & 1.02 & 1.06 & $1.17^{*}$ & 1.33 & 1.43 & 1.53 & 1.57 & 1.67 \\
\hline \multicolumn{10}{|c|}{ Galena Summit } \\
\hline \multicolumn{10}{|l|}{ Water equivalent, inches } \\
\hline March 1 & 10.9 & 12.8 & 14.8 & $19.9^{*}$ & 26.2 & 30.0 & 33.3 & 34.3 & 37.4 \\
\hline April 1 & 15.0 & 17.1 & 19.3 & $24.7^{*}$ & 31.1 & 34.2 & 38.2 & 39.3 & 42.3 \\
\hline $\begin{array}{l}\text { April: March contingency water } \\
\text { equivalent ratio }\end{array}$ & 1.07 & 1.11 & 1.14 & 1.23 & 1.35 & 1.43 & 1.49 & 1.52 & 1.58 \\
\hline
\end{tabular}

* These data were used in the examples in the text. 
TiBLE 2. Mean Error $\bar{X}$ of the Absolute Difference between the Estimated April Snow Water Parameters and the Corresponding Measured Parameters and the Standard Error of the Mean $s$ and the Coefficient of Determination $r^{2}$ between the Estimated and Measured Values for Three Sites for 1950-1971

\begin{tabular}{|c|c|c|c|c|c|c|}
\hline & \multicolumn{3}{|c|}{ Recurrence Analysis } & \multicolumn{3}{|c|}{ Linear Regression Annalysis } \\
\hline & $\bar{X}$ & $s$ & $r^{2} \times 100$ & $\bar{X}$ & 8 & $r^{2} \times 100$ \\
\hline \multicolumn{7}{|c|}{ Snow Depth } \\
\hline \multicolumn{7}{|l|}{ Method 1} \\
\hline Galena Summit & 8.0 & 6 & 70 & 8.7 & 6 & 70 \\
\hline Galena & 9.3 & 6 & 72 & 10.7 & 7 & 68 \\
\hline Graham Ranch & 13.5 & 10 & 70 & 14.6 & 11 & 65 \\
\hline Average & 10.3 & 7 & 71 & 11.3 & 8 & 68 \\
\hline \multicolumn{7}{|l|}{ Method 2} \\
\hline Galena Summit & 9.4 & 8 & 70 & 9.5 & 8 & 70 \\
\hline Galena & 11.0 & 10 & 70 & 10.3 & 11 & 70 \\
\hline Graham Ranch & 13.4 & 9 & 70 & 12.6 & 11 & 67 \\
\hline Average & 11.3 & 9 & 70 & 10.8 & 10 & 69 \\
\hline \multicolumn{7}{|l|}{ Method 3} \\
\hline Galena Summit & 6.8 & 6 & 84 & 7.0 & 6 & 84 \\
\hline Galena & 8.8 & 8 & 77 & 7.8 & 6 & 79 \\
\hline Graham Ranch & 11.4 & 9 & 68 & 9.4 & 8 & 84 \\
\hline Average & 9.0 & 8 & 76 & 8.1 & 6 & 82 \\
\hline \multicolumn{7}{|c|}{ Water Equivalent } \\
\hline Method 1 & & & & & & \\
\hline Galena Summit & 6.2 & 5 & 92 & 5.9 & $\mathbf{5}$ & 92 \\
\hline Galena & 8.3 & 5 & 90 & 8.6 & 6 & 88 \\
\hline Graham Ranch & 11.4 & 9 & 88 & 9.9 & 12 & 88 \\
\hline Average & 8.6 & 7 & 90 & 8.1 & 8 & 89 \\
\hline \multicolumn{7}{|l|}{ Method 2} \\
\hline Galena Summit & 9.6 & 9 & 82 & 9.5 & 7 & 84 \\
\hline Galena & 10.5 & 8 & 86 & 9.3 & 10 & 86 \\
\hline Graham Ranch & 13.0 & 8 & 82 & 12.0 & 9 & 82 \\
\hline Average & 11.0 & 8 & 84 & 10.3 & $\mathbf{q}$ & 84 \\
\hline \multicolumn{7}{|l|}{ Method 3} \\
\hline Galena Summit & 5.3 & 5 & 96 & 6.1 & 3 & 96 \\
\hline Galena & 8.4 & 7 & 90 & 8.2 & 5 & 94 \\
\hline Graham Ranch & 10.6 & 9 & 82 & 8.5 & 9 & 92 \\
\hline \multirow[t]{2}{*}{ Average } & 8.1 & 7 & 89 & 7.6 & 6 & 94 \\
\hline & \multicolumn{3}{|c|}{ Snow Density } & & & \\
\hline \multicolumn{7}{|l|}{ Method 1} \\
\hline Galena Summit & 6.3 & 4 & 60 & 5.8 & 4 & 58 \\
\hline Galena & 5.8 & 6 & 59 & 5.2 & 5 & 61 \\
\hline Graham Ranch & 6.7 & 6 & 33 & 6.4 & 4 & 31 \\
\hline Average & 6.3 & 5 & 51 & 5.8 & 4 & 50 \\
\hline \multicolumn{7}{|l|}{ Method 2} \\
\hline Galena Summit & 3.9 & 4 & 79 & 3.8 & 3 & 77 \\
\hline Galena & 3.9 & 3 & 77 & 4.1 & 3 & 79 \\
\hline Graham Ranch & 4.5 & 4 & 64 & 4.3 & 4 & 66 \\
\hline Average & 4.1 & 4 & 74 & 4.1 & 4 & 74 \\
\hline \multicolumn{7}{|l|}{ Method 3} \\
\hline Galena Summit & 6.2 & 4 & 67 & 5.1 & 4 & 71 \\
\hline Galena & 6.0 & 6 & 60 & 4.9 & 5 & 71 \\
\hline Graham Ranch & 12.0 & 9 & 16 & 10.1 & 7 & 29 \\
\hline Average & 8.1 & 6 & 48 & 6.7 & 6 & 57 \\
\hline
\end{tabular}

Method 3. This analysis method (equal site to site contingency) uses the contingency ratio (Figure 2) that occurred at site $A$ to select the contingency ratio at site $B$ having the same recurrence interval as the contingency ratio at site $A$. To determine the estimated value for the second month, the estimated contingency ratio for site $B$ is then multiplied by the pa- 
rameter value at site $B$ measured on the first of the two consecutive months composing the contingency ratio.

Method 3 assumes that the contingency ratios for the two sites being considered have the same recurrence intervals for the estimating periods. The coefficient $b$ for the regression of the Galena Summit water equivalent contingency ratio (April:March) on that for Mount Baldy was $b=0.71$. An example of the application of this method follows. If the measured April:March water equivalent contingency ratio at Mount Baldy is 1.17 and the measured March water equivalent at Galena Summit is 30.0 inches, an estimate of the April water equivalent for Galena Summit can be made. Since the Mount Baldy April:March water equivalent contingency ratio is at the $50 \%$ recurrence interval (Table 1), the April: March water equivalent contingency ratio expected at Galena Summit should also be at the $50 \%$ recurrence interval. Therefore, the April: March Galena Summit water equivalent contingency ratio expected is 1.23 , and the estimated April water equivalent is $1.23 \times 30.0$ inches, or 36.9 inches. Estimates computed by method 3 when they were compared to the 1950-1971 measured April water equivalent values at Galena Summit had a coefficient of determination of 0.96 .

\section{Regression Estimating Methods}

Regression analysis was performed on the measured snow water parameters for 19501971. By use of method 1 the April snow water parameter for example, was regressed on the March parameter at the same site. With method 2 the snow water parameter for a given month at site $A$ was regressed on the same parameter for the same month at site B. By use of method 3 , contingency ratios of site $A$ were regressed on those of site B for the same estimating period. For single independent parameters, linear regression resulted in better correlations than nonlinear regression with any one of five curve types tested.

\section{Evaluation of Estimating Methods}

Each April snow water parameter for 19501971 was estimated for three sites by using three methods for both recurrence and regression procedures (Table 2). For example, by use of method 1 the absolute differences between the estimated April data, estimated from recurrence or regression analysis, and the April measured values were calculated. The absolute error was determined as $(d / m) 100$, where $d$ is the absolute value of the difference between the estimated and the measured parameter and $m$ is the measured value of the parameter. The mean $\bar{X}$ and standard error $s$ were calculated for the absolute error and are shown in Table 2. The coefficient of determination $r^{2}$ between the measured data and the values estimated from either the recurrence or the regression method is also shown (Table 2). These computations were repeated for each of the three methods and each of the three snow water parameters.

The statistical parameters $\bar{X}$ and $s$ and the coefficient of determination $r^{2}$ indicate that estimates for Galena Summit, Galena, and Graham ranch were similar when either the recurrence analysis or a regression analysis was used.

Method 3 (site to site contingency), compared to methods 1 or 2 , seems to be the better technique for estimating the snow depth at any of the three sites. Method 3 on the average accounts for $76 \%$ of the observed variation between measured snow depths, as compared with $70 \%$ for methods 1 and 2, and, in general, method 3 has a somewhat smaller absolute error.

Methods 1 and 3 are superior to method 2 for estimating water equivalent because they account for an average of $90 \%$ of the variation of measured water equivalent, as compared to only $84 \%$ by method 2 . The magnitude of the absolute error also indicates the superiority of methods 1 and 3 .

Method 2 accounted for $74 \%$ of the variation in measured snow densities, compared to about $50 \%$ by methods 1 and 3 . The $r^{2}$ values for snow density, however, are considerably lower than those calculated for snow depth and water equivalent parameters. The absolute errors between the estimated values and the actual values of stibw density were on the average less by method 2 than by methods 1 and 3 . The relative magnitude of errors in estimating snow density was smaller than that of errors calculated for snow depth and water equivalent (Table 2).

The larger errors observed for Graham ranch 
measurements, compared to errors for Galena and Galena Summit, may be accounted for by the initiation of snowmelt in some years at the lower elevation site (Graham ranch) by April 1. In fact, the average absolute error is inversely proportional to the elevation of the sites (Figure 1).

The evaluations implied by the results shown in Table 2 could be questioned, however, since the estimating formulas were based on a data set containing each of the individual entries. Therefore the utility of the proposed methods was evaluated by using 1972 data, which had not been used in the original analysis.

April 1972 snow water parameters were estimated for the Galena Summit, Galena, and the Graham ranch sites by using both the recurrence analysis and the regression analysis and all three estimating methods (Table 3 ). Mount Baldy was again used as a reference site in methods 2 and 3.

The relative magnitude of absolute errors associated with the three estimating methods for snow depth, water equivalent, and density does not indicate the same order of method preference as suggested by the 1950-1971 data
(Table 2). However, $75 \%$ of the absolute errors shown in Table 3 are within 1 standard deviation of the error of the 1950-1971 data sets (Table 2), a near normal distribution of the error statistic being indicated. The recurrence analysis and the regression analysis produce similar results for each method on the three courses (Table 3 ).

The data given in Table 3 do not suggest any one best method for estimating the snow water parameters because of the limited number of sites examined. The method preference indicated by analysis of the 22-year data set is still preferred.

\section{Discussion}

It was found that both the recurrence analysis and the linear regression analysis produced similar results when the three estimating methods were applied to snow water data from several sites in central Idaho. The recurrence technique presented is a reliable procedure that can be used to estimate snow water parameters and to supplement or provide added confidence to data obtained from simple linear regression. In prediction of the snow water parameters at a

TABLE 3. Estimated Snow Depth, Water Equivalent, and Snow Density Values Compared to Measured Values for April 1, 1972, at Three Sites

\begin{tabular}{|c|c|c|c|c|c|c|}
\hline & \multicolumn{3}{|c|}{ Recurrence Analysis } & \multicolumn{3}{|c|}{ Linear Regression Analysis } \\
\hline & $\begin{array}{c}\text { Galena } \\
\text { Summit }\end{array}$ & Galena & $\begin{array}{c}\text { Graham } \\
\text { Ranch }\end{array}$ & $\begin{array}{l}\text { Galena } \\
\text { Summit }\end{array}$ & Galena & $\begin{array}{l}\text { Graham } \\
\text { Ranch }\end{array}$ \\
\hline \multicolumn{7}{|c|}{ Snow Depth, inches } \\
\hline Measured & 85 & 60 & 34 & 85 & 60 & 34 \\
\hline Estimated & & & & & & \\
\hline Method 1 & $95(12)$ & $75(25)$ & $39(15)$ & $92(8)$ & $73(21)$ & $40(18)$ \\
\hline Method 2 & $78(8)$ & $64(7)$ & $42(24)$ & $90(6)$ & $62(3)$ & $44(29)$ \\
\hline Method 3 & $95(12)$ & $74(23)$ & $36(6)$ & $96(13)$ & $75(25)$ & $37(9)$ \\
\hline \multicolumn{7}{|c|}{ Watcr Equivalent, inches } \\
\hline Measured & 31.6 & 23.4 & 12.5 & 31.6 & 23.4 & 12.5 \\
\hline Estimated & & & & & & \\
\hline Method 1 & $32.4(3)$ & $25.5(9)$ & $14.3(14)$ & $32.4(3)$ & $25.0(7)$ & $14.6(17)$ \\
\hline Method 2 & $26.9(15)$ & $22.0(6)$ & $14.1(13)$ & $26.8(15)$ & $21.6(8)$ & $15.0(20)$ \\
\hline Method 3 & $33.9(7)$ & $26.5(13)$ & $14.4(15)$ & $34.0(8)$ & $16.4(13)$ & $14.3(14)$ \\
\hline \multicolumn{7}{|c|}{ Snow Density } \\
\hline Measured & 0.372 & 0.390 & 0.368 & 0.372 & 0.390 & 0.368 \\
\hline Estimated & & & & & & \\
\hline Method 1 & $0.33 \dot{8}(9)$ & $0.334(14)$ & $0.355(3)$ & $0.344(8)$ & $0.340(13)$ & $0.340(8)$ \\
\hline Method 2 & $0.349(6)$ & $0.349(11)$ & $0.343(7)$ & $0.349(6)$ & $0.347(11)$ & $0.337(8)$ \\
\hline Method 3 & $0.366(2)$ & $0.298(24)$ & $0.276(25)$ & $0.364(2)$ & $0.366(6)$ & $0.308(16)$ \\
\hline
\end{tabular}

Numbers in parentheses indicate percentage of error in absolute terms. 
particular site, neither the recurrence analysis nor the regression analysis appears consistently superior. Intuitively, the utility of either recurrence or regression analysis to estimate snow water parameters is improved as the size of the basic data set increases.

Although this recurrence analysis estimating technique was tested on only four central Idaho snow course sites, the analysis and methods should be applicable also to other snow course sites in Idaho as well as other states. The reliability of predicting April snow water parameters from the Mount Baldy base site was greatest for Galena Summit, less for Galena, and least for the Graham ranch site. This ranking of sites corresponds to decreasing elevation of the sites and the greater probability for melt to occur earlier at lower elevations. Exposure would also be an important factor in timing snowmelt.

This proposed technique should be evaluated and improved further. The various recurrence curves could be analyzed by using variables such as the mean, standard deviation, coefficient of skew, elevation, and site exposure to select the base sites best suited for use with methods 2 and 3. These same variables might also be used in a multiple-regression analysis to improve the accuracy of the prediction.

Acknowledgment. The authors thank Dr. M. Molnau, University of Idaho, Moscow, for his helpful suggestions.

\section{REFERENCES}

Langbein, W. B., Plotting positions in frequency analysis, in Flood-Frequency Analysis, edited by T. Dalrymple, U.S. Geol. Surv. Water Supply Pap. 1549-A, 48-51, 1960.

Soil Conservation Service, Idaho snow survey measurements, 1921-1964.

Soil Conservation Service, Basic data summary for western United States, 1965-1971.

U.S. Water Resources Council, A uniform technique for determining flood flow frequencies, Bull. 15, pp. 7-8, Hydrol. Comm., Water Resour. Counc., Washington, D. C., 1967.

Vance, H. M., and B. L. Whaley, Snow frequency analysis for Oregon and Utah, paper presented at 39th Annual Meeting, West. Snow Conf., Billings, Mont., April 1971.

(Received March 2, 1973; revised April 17, 1973.) 